\title{
Method for the Localization of Incompetent Ankle Perforating Veins
}

\author{
A. S. CHILVERS, ${ }^{*}$ M.A., F.R.C.S. ; M. H. THOMAS, $†$ M.B., B.S.
}

British Medical fournal, 1970, 2, 577-579

\begin{abstract}
ummary: A test for localizing incompetent ankle perforating veins uses an injection of fluorescein into a vein on the dorsum of the foot, with subsequent scanning of the leg under ultraviolet light. The test was found to be $96 \%$ accurate, \& 1 to be simple, safe, and cheap. It is considered to be particularly suitable for assessing legs with very early changes and with recurrent varicose veins.
\end{abstract}

\section{Introduction}

The accurate diagnosis of incompetent ankle perforating veins is of great importance in planning effective treatment of varicose veins (Linton, 1938; Dodd and Cockett, 1965). Ligation of these veins was described by Linton (1938) and by Cockett and Jones (1953). After studying 500 cases Dodd (1964) reaffirmed the importance of the procedure. Fegan and Fitzgerald (1963) re-emphasized this and described a technique for compression sclerotherapy. The diagnosis of incompetent ankle perforating veins is made from the history, clinical examination, and special tests. The clinical diagnosis has been well covered by others (Cockett and Jones, 1953; Dodd, 1964; Dodd and Cockett, 1965; Fegan, 1967). Careful clinical assessment can give a correct localization of $69 \%$ of incompetent ankle perforating veins (Townsend, Jones, and Williams, 1967).

Various tests have been devised to help location. The tourniquet tests (Brodie, 1846; Trendelenburg, 1891; Bracey, 1958), auscultation (Dost, 1968), phlebography (Dos Santos, 1938; Massell and Ettinger, 1948; Cockett, 1953; Begg, 1954; Townsend et al., 1967), and skin thermography (Rosenberg and Marchese, 1963; Rosenberg and Stefanides, 1964; Williams, 1964; Patil, Williams, and Lloyd Williams, 1970) have all been advocated, but only phlebography and thermography have been shown to be valuable. Dynamic thermography can give correct localization of incompetent perforating veins in 94.5\% (Patil et al., 1970) but requires considerable apparatus and expense. Phlebography can demonstrate $92 \%$ of incompetent ankle perforating veins (Townsend et al., 1967), but though it is an effective method it is difficult to transfer the two dimensional film localization to the three dimensions of the leg (Dow, 1951).

A simple bedside test is needed that will both diagnose and accurately locate incompetent ankle perforating veins. This paper describes a test that we feel meets those requirements.

\section{Methods}

\section{Case Selection and Clinical Assessment}

This study aimed to compare the fluorescein test with operation findings. Accepting that clinical methods of location were unreliable we made no attempt to locate the exact site of the incompetent perforating veins by clinical examination. To have a high incidence of incompetent perforating veins in the legs we were to study, however, we chose patients who had clinical evidence of perforator incompetence in at least one leg and long saphenous incompetence-namely, 'severe aching on exercise, ankle oedema, eczema, pigmentation, or ulceration and failure to control the veins with a tourniquet below the knee. Thus a clinical diagnosis of the presence or absence of incompetent ankle perforating veins was made

* Senior Surgical Registrar, St. Thomas's Hospital, London S.E.1. † House-Surgeon, St. Thomas's Hospital, London S.E.1. without attempting to define the actual anatomical site of each one. All the legs were assessed clinically by one of us and then examined blindly with the fluorescein test by the other.

\section{Technique of Fluorescein Test}

The patient lies on his back on a suitable table or couch; to obtain the best result he should be tilted foot-down about $10^{\circ}$. A $2 \cdot 5-\mathrm{cm}$. wide sphygmomanometer cuff is placed round the ankle, just above the malleoli, and inflated to $80 \mathrm{~mm}$. $/ \mathrm{Hg}$. With practice this cuff can be replaced by a piece of rubber tubing or Setoniquet. A second sphygmomanometer cuff of normal width $(13 \mathrm{~cm}$.) is placed above the knee. A vein is chosen on the dorsum of the foot as lateral and distal as possible, as for the St. Thomas's method of phlebography (Browse, Lea Thomas, and Solan, 1967), but if such a vein is not available any vein on the dorsum of the foot can be used. The leg is then raised vertically and the patient asked to plantar-f $f^{\prime}$. 1 foot 10 times. This pumps the venous blood out of 1 - calf and empties any superficial varices. The upper cuff is now inflated to $120 \mathrm{~mm}$. $/ \mathrm{Hg}$ and the leg lowered. The selected vein is punctured towards the toes and $5 \mathrm{ml}$. of $5 \%$ aqueous fluorescein slowly injected ( 30 seconds). The room is blacked out and an ultraviolet light shone on the leg. (We have used a Hanovia Kromayer IX SK 220, with Wood's filter, borrowed from the physiotherapy department.)

The patient again plantar-flexes his foot 10 times. This draws the dye into the deep venous system of the calf, entry into the superficial system of the calf being prevented by the ankle cuff, and then forces it out from the deep veins into the superficial veins through any perforating veins that have incompetent valves. If the leg is large or very indurated we inject $10 \mathrm{ml}$. of dye. When the ultraviolet lamp i: shone on the leg from a distance of about $3 \mathrm{ft}$. $(90 \mathrm{~cm}$.) the site of the incompetent perforating veins is shown by a small circle of green-yellow fluorescence $1-2 \mathrm{~cm}$. in diameter (Figs. 1 and 2). These fluorescent areas, which take between 30 seconds and 2 minutes to appear, are marked with a felt pen. Occasionally a second or third series of pumps is necessary. Any leakage into the superficial system under the lower tourniquet immediately becomes obvious (Fig. 3). False-positive marks can be produced as the fluorescein spreads through the superficial veins if the test continues for more than two minutes.

There have been no complications from the fluorescein injection. Nausea and vomiting are the reported side-effects of intravenous fluorescein (Gasul, Marino, and Christian,

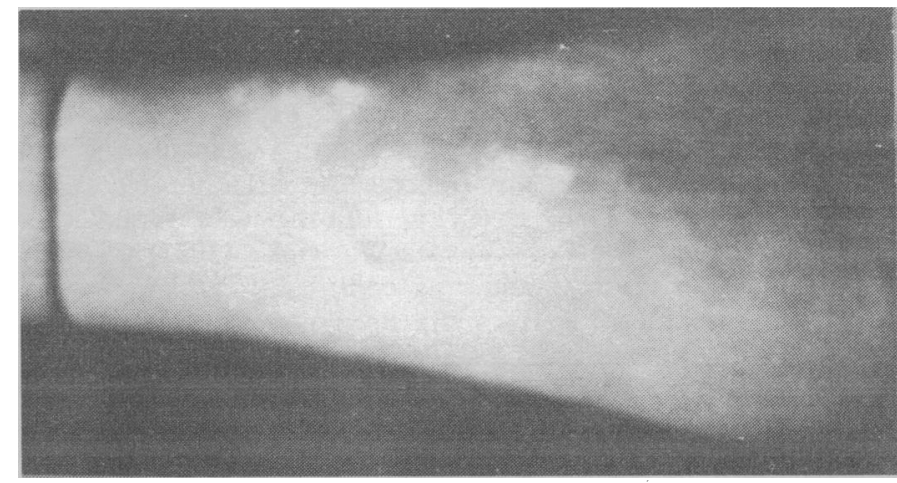

FIG. 1.-A positive test. This photograph, taken two minutes after exercising the calf muscles, shows two positive marks. There is already
a slight spread of dye from the original marks to the surrounding skin. 


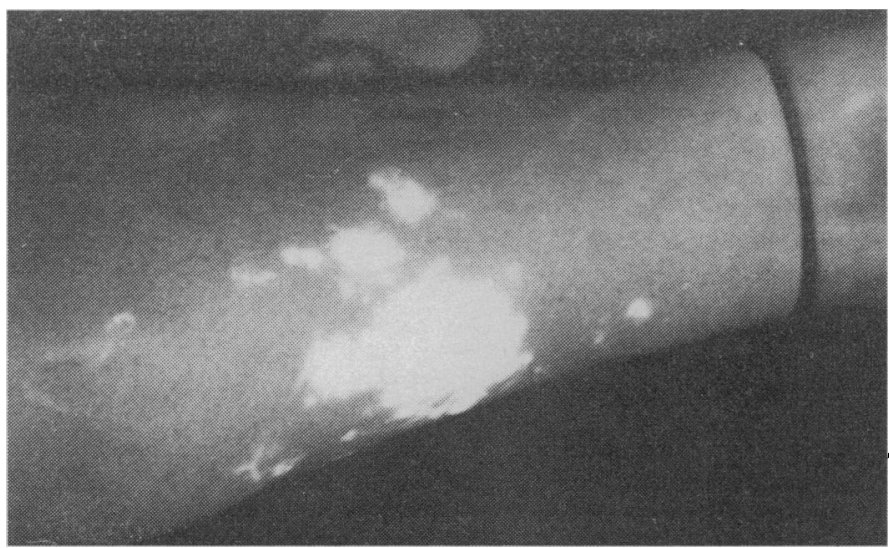

Fig. 2.-Spread of fluorescein from a positive test. One minute after calf exercise this leg showed one small fluorescent area. This photocalf exercise this leg showed one small fluorescent area. This photograph, taken five minutes later, shows the spread of the dye and the
development of satellite areas of fluorescein. These are not additional incompetent perforating veins.

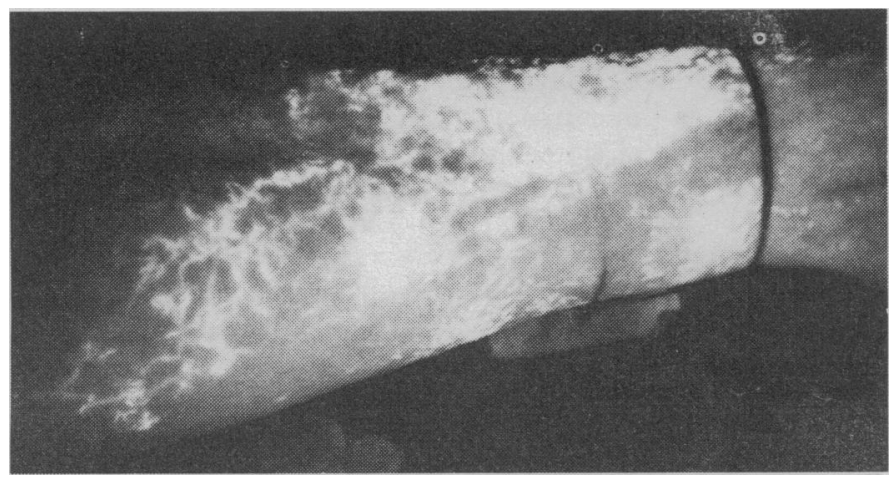

FIG. 3.-Leakage of fluorescein under the lower tourniquet is usually obvious because of its site and reticular pattern.

1949; Macgregor and Wayne, 1951), but these have occurred only after large doses. The urine may turn green for a short period after the test and the patients should be warned of this. The lamp is perfectly safe if shone from 2 to $3 \mathrm{ft}$. (60 to $90 \mathrm{~cm}$.) away from the leg. The exposure time of about five minutes per leg is well below the limit that may produce burns. Patients and operators should not look directly at the light.

\section{Operation}

All legs with a clinical diagnosis of incompetent perforating veins or a positive fluorescein test were explored by a 6-in. $(15-\mathrm{cm}$.) incision behind the medial border of the tibia. Local incisions were made over any fluorescein marks not accessible from the main incision. Every perforating vein found was tested for incompetence by Turner Warwick's (1931) method; the vein was cut across and was considered incompetent if there was free bleeding from the deep compartment. If the deep end of a perforating vein did not bleed a probe was passed into it to ensure that it was patent. This allowed back bleeding, which stopped when the probe was withdrawn. Legs with no clinical evidence of incompetent perforating veins and a negative fluorescein test had a limited exploration of the ankle and the region of the perforating veins was not explored.

\section{Results}

The Patients.-Twenty patients admitted for varicose vein surgery were studied; a total of 37 legs (19 female and 18 male).

Clinical Assessment.-Twenty-six legs had clinical evidence of incompetent ankle perforating veins. Most had pigmentation and eczema, and all had veins that were not controlled by a tourniquet just below the knee. All the legs had long saphenous incompetence. Eleven legs had no clinical evidence of incompetent perforating veins. Thus one-third of the legs had pure long saphenous incompetence without clinical evidence of perforating vein incompetence.

Fluorescein Assessment.-Of the 37 legs, 27 had a positive fluorescein test. In these 27 legs there were 54 fluorescein spots. The maximum number of spots in one leg was six; most had two or three. All but one of the legs had clinical evidence of incompetent perforating veins-that is, only one of the legs which was negative clinically had a positive fluorescein test. All the marks were on the medial side of the leg.

Operative Assessment.-Incompetent perforating veins were found at operation in 27 of the 37 legs. The maximum number of incompetent veins found was six; most had two or three. Fifty-two incompetent veins were found in all. Of these, 51 were in clinically positive legs and one was in a clinically negative leg.

\section{Fluorescein Test and Operative Findings}

Of the 52 incompetent veins found at operation, $50(96 \%)$ were accurately located by the test (see Table). Thirty-three passed directly through the deep fascia to the mark, 17 passed obliquely to the mark. None of the oblique veins passed through the deep fascia more than $3 \mathrm{~cm}$. from the fluorescein mark. All of them connected with a vein immediately underneath the mark, and the defect in the deep fascia could always be reached through the incision over the mark. Two (4\%) of the incompetent veins found at operation were not detected by the fluorescein test; in both cases they were overlain by gross varices which did not connect directly with the incompetent perforator. Four ( $8 \%$ ) marks did not have an incompetent perforating vein below them.

Incompetent Ankle Perforating Veins Found at Operation. Results in 37 Legs

\begin{tabular}{c|c|c|c}
$\begin{array}{c}\text { Incompetent Veins } \\
\text { Found at Operation }\end{array}$ & $\begin{array}{c}\text { Incompetent Veins } \\
\text { with Marks }\end{array}$ & $\begin{array}{c}\text { Incompetent Veins } \\
\text { with No Marks }\end{array}$ & $\begin{array}{c}\text { Marks with No } \\
\text { Incompetent Veins }\end{array}$ \\
\hline 52 & $50(96 \%)$ & $2(3 \cdot 8 \%)$ & $4(7 \cdot 7 \%)$
\end{tabular}

The anatomical sites of perforating veins and dye marks are shown in Fig. 4. The clinically negative leg with a positive fluorescein test had a single incompetent perforating vein below the mark. The 10 other clinically negative legs were negative to the fluorescein test and were not explored at operation. Seven of the fluorescein-located incompetent veins could not be reached through the standard 6-in. (15$\mathrm{cm}$.) incision and would have been missed without the test.

\section{Discussion}

The accurate localization of incompetent perforating veins is an essential preliminary to the proper treatment of varicose veins. The existing methods require expensive apparatus and are lengthy. Our test is simple, safe, and cheap; moreover, it 


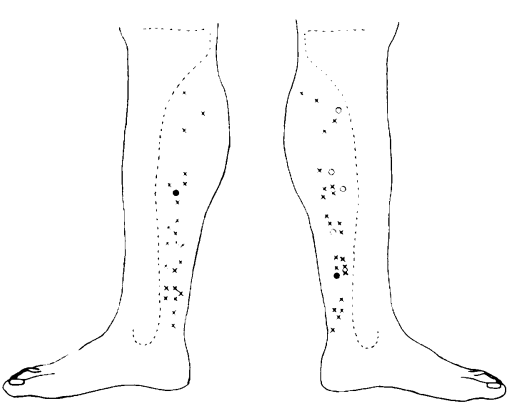

FIG. 4.-Diagram showing anatomical sites of perforating veins and dye marks. $\mathrm{X}=$ Correct localization of incompetent vein by fluorescein. $\mathrm{O}=$ False-positive fluorescein mark. = Incompetent vein without fluorescein mark (false negative). There were no marks on the lateral aspect of the 37 legs studied. Not all the marks are shown as there was reduplication of sites.

can be done in 10 minutes and does not distress the patient. The only equipment required is the ultraviolet gun, which can be borrowed from the physiotherapy department. Fluorescein was chosen for this test because it is safe and in normal light does not colour the patient, whereas under ultraviolet light it is easily seen even through indurated, pigmented, or ulcerated skin. It is also detectable in very lo concentrations.

We have shown that the fluorescein test has a high degree of accuracy $(96 \%)$ both for diagnosis and exact skin localization. The test produced $4 \%$ false negatives and $8 \%$ false positives. The former occurred where very large varices overlaid the perforating veins but did not connect with them. This prevented the dye reaching the skin. The false positives were probably due to spread of the dye within the superficial veins. We noted that small areas of fluorescence appeared around the initial mark, and at first we thought that these were additional perforating veins. When operation proved that this was not the case we shortened the time limit of the experiment to two minutes and almost abolished the falsenegative results. In the main series there were only two false positives, and as they both occurred in legs with other true positive marks no leg was explored unnecessarily.

Filling of superficial varices can be a problem with almost any case unless the tourniquets are adjusted properly. The lower one needs to be inflated to $80 \mathrm{~mm}$./ $\mathrm{Hg}$ to prevent leakage from the foot, but if this tourniquet is too tight the deep veins are also obstructed. The upper (thigh) cuff must be inflated to $120 \mathrm{~mm} . / \mathrm{Hg}$ to prevent blood leaking down from the thigh and filling the superficial varices. This will dilute the fluorescein and make the marks more difficult to see. The pressure in the upper cuff must also be high enough to obstruct the deep system so that the calf contractions force the blood into the superficial veins and not up into the thigh. Poor results will occur if the calf pumping action is not effectively carried out. We rehearse the manoeuvre with the patient with care before the test is begun.

It appears from our study that incompetence of the long saphenous vein can be a primary phenomenon and is not always associated with incompetent perforating veins as has been suggested by Fegan (1967). Twenty-seven per cent. of our cases had primary long saphenous incompetence. All legs with a clinical diagnosis of incompetent perforating veins, on our criteria, had incompetent veins at operation. We feel that the fluorescein test, though applicable to all legs, is particularly useful in the assessment of legs with very early or no ankle changes and of those difficult legs with recurrent varicose veins. It can be done as easily on outpatients as on inpatients. We now use this test routinely on all our patients with varicose veins and are assessing its value in the diagnosis and localization of thigh perforating veins. A survey of the incidence of incompetent perforating veins in apparently normal legs is also being undertaken.

We are grateful to Professor J. B. Kinmonth and Mr. Norman Browse for allowing us to test patients under their care, to $\mathrm{Mr}$. Browse for his help and advice in devising this test, and to Dr. $M$. Lea Thomas for teaching us his method of filling the deep veins.

\section{REFERENCES}

Begg, A. C. (1954). British fournal of Radiology, 27, 318. Bracey, D. W. (1958). British Medical fournal, 2, 101.

Brodie, Sir B. C. (1846). Lectures Illustrative of Various Subjects in Pathology and Surgery. London, Longman.

Browse, N. L., Lea Thomas, M., and Solan, M. J. (1967). British Medical fournal, 4, 596.

Cockett, F. B. (1953). British fournal of Radiology, 26, 339.

Cockett, F. B., and Jones, D. E. E. (1953). Lancet, 1, 17.

Dodd, H. (1964). Annals of the Royal College of Surgeons of England,

34, 186. Veins of the Lower Limb. Edinburgh, Livingstone.

Dos Santos, J. C. (1938). fournal International de Chirurgie, 3, 625.

Dost, K. (1968). German Medical Monthly, 13, 335.

Dow, J. D. (1951). British fournal of Radiology, 24, 182.

Fegan, W. G., and Fitzgerald, D. E. (1963). Irish fournal of Medical Sciences, p. 439. Fegan, W. G. (1967). Annals of the Royal College of Surgeons of Gasul, B. M., Marino, J. J., and Christian, J. R. (1949). Fournal of
Pediatrics, 34, 460.

Linton, R. R. (1938). Annals of Surgery, 107, 582.

Macgregor, A. G., and Wayne, E. J. (1951). British Heart fournal, 13, 80 .

Massell, T. B., and Ettinger, J. (1948). Annals of Surgery, 127, 1217.

Patil, K. D., Williams, J. R., and Williams, K. L. (1970). British Medical fournal, 1, 195.

Rosenberg, N., and Marchese, F. P. (1963). Surgery, 53, 575.

Rosenberg, N., and Stefanides, A. (1964). Annals of the New York Academy of Sciences, 121, 113 .

Townsend, J., Jones, H., and Williams, J. E. (1967). British Medical fournal, 3, 583.

Trendelenburg, F. (1891). Beiträge zur Klinischen Chirurgie, 7, 195.

Warwick, W. T. (1931). The Rational Treatment of Varicose Veins and Varicocoele, p. 60. London, Faber and Faber.

Williams, K. L. (1964). Annals of the New York Academy of Sciences, 